\title{
Editorial
}

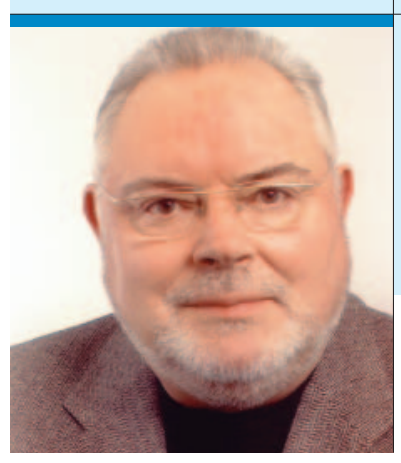

„HNO-Kollegen, die sich durch alle Ausbildungslücken

zum Assistenzarzt ohne Zeitvertrag durchgeboxt haben, verlassen ihre sichere Klinikstelle nur ungern."

\section{Das alte Hin und Her}

E $s$ vergeht kein Tag ohne Hiobsbotschaften über den derzeitigen Ärztemangel: Unterversorgung in ländlichen Gebieten und zu wenig Fachärzte auch in vermeintlich gut versorgten Regionen. Laut KBVChef Köhler fehlen derzeit in Deutschland rund 3.600 Praxisärzte. Alles schon mal da gewesen. Nach meinem Staatsexamen 1968 zu Beginn der noch üblichen Medizinalassistentenzeit wurde man in den Krankenhäusern mit erwartungsvoller Freude empfangen: „Endlich kann ich mal in Urlaub fahren, bei dem Oberschenkelhalsbruch von Zimmer 10 hängst Du zweieinhalb Kilo an den Streckverband. Wenn's mal buttert ist Supracillin das Mittel der Wahl, wirkt immer." Das war die Begrüßung durch den chirurgischen Stationsarzt. Bewundert wurde aber insgeheim der ältere Stationspfleger, genannt „Wärter Schwager", der $6 \mathrm{~cm}$ breites Leukoplast mit bloßen Händen durchreißen konnte.

Ein gravierender Ärztemangel war jeden Tag sichtbar, die Assistenzärzte wurden in Kreiskrankenhäusern vorwiegend aus süditalienischen Regionen rekrutiert. Völlig anders war die Situation jedoch, wenn man eine Facharzt-Ausbildung an einer renommierten Klinik anstrebte. Erst mal zwei Jahre Pathologie, dann sehen wir weiter, war das übliche Chefurteil. Wenn man an eine Stationstür klopfte, riefen die Kollegen zum Entree: „Komm rein, wenn's kein Facharzt ist!" Wenige Jahre später war der Zustrom ausbildungswilliger Kollegen plötzlich versiegt.

\section{Zyklische Entwicklungen}

Heute erleben wir diese wellenförmigen Bewegungen wieder. Obwohl die Zahl der Studienabbrecher in der Medizin mit nur 5\% gering ist, bleiben später viele Stellen unbesetzt. Ein Super-Einser-Abitur zum Einstieg in die Medizinzunft hat absolut keinen Fortschritt gebracht, auch die Ausbildungsqualität gerade in den operativen Fächern ist dadurch keineswegs besser geworden.
Wo bleibt also der medizinische Nachwuchs? Sicher ist die Zahl der Ausbildungsstellen an den Kliniken zu gering, aber die HNO-Kollegen, die sich durch alle Ausbildungslücken zum Assistenzarzt ohne Zeitvertrag durchgeboxt haben, verlassen ihre sichere Klinikstelle nur ungern. Und wenn, gehen sie lieber in die Großstadt und lassen sich auf der anderen Straßenseite gegenüber vom HNO-Kollegen nieder. Kassenpraxis, nein danke!

Einer Studie der Ruhr-Universität Bochum zufolge planen nur $22 \%$ von 4.000 befragten Medizinstudenten sich niederzulassen. Ganze $73 \%$ der $\mathrm{Ab}-$ solventen können sich vorstellen ins Ausland zu gehen, $38 \%$ ziehen eine patientenferne Tätigkeit in Erwägung. Ungünstige Arbeitszeiten, die Budgetierung und die schlechte Vergütung ärztlicher Leistungen schrecken die Studenten ab. Die aktuellen Zahlen sprechen für sich. Die Bundesbürger verdienen nach einer aktuellen Studie weniger als vor 20 Jahren, Zuwächse wurden von der Inflation aufgefressen. Besonders dramatisch ist der Einbruch bei den Ärzten: Sie stehen mit einem realen Minus von $50 \%$ an der Spitze der Verlierer. Der ideelle und materielle Wert bei einer „normalen“ Praxisübernahme tendiert eher gegen Null. In ländlichen Regionen ist zu beobachten, dass Landarztstellen auch in nicht allzu attraktiven Dorfregionen eher besetzt werden können als Facharztplätze in Kleinstädten mit guter Infrastruktur. Ob das so bleibt?

Immerhin, die Zahl der offenen Vertragsarztsitze ist in den letzten zehn Jahren um 30\% zurückgegangen. Bleiben wir also zuversichtlich!

Ihr

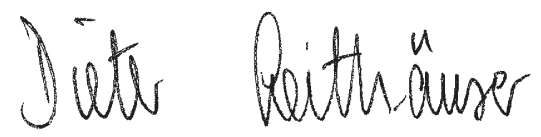

